\title{
Examining the preparation and characterization of coatings based on linear aromatic terpoly(methoxy-cyanurate- thiocyanurate)s
}

\author{
Ian Hamerton, ${ }^{*}$ Brendan J. Howlin and David A. Tilbrook ${ }^{\dagger}$
}

\begin{abstract}
Two series of terpoly(methoxy-cyanurate-thiocyanurate)s based on thiodiphenol and dithiodiphenyl sulfide and on dihydroxydiphenyl ether and dithiodiphenyl ether, were prepared in good yield and purity and fully characterized. Most of the resulting polymers, formed at room temperature using phase transfer catalysis, can be cast into films with good resilience and thermal stability (some examples suffer practically no mass loss when held isothermally at $190{ }^{\circ} \mathrm{C}$ and only display appreciable losses when held continuously at $225^{\circ} \mathrm{C}$ ). Char yields of $53 \%-61 \%$ are achieved in nitrogen depending on backbone structure. Some problems were encountered with solubility, particularly with copolymers, which limited molecular weight analysis, but values of $M_{\mathrm{n}}=8000-13000 \mathrm{~g} \mathrm{~mol}^{-1}$ were obtained for the polymers based on thiodiphenol and dithiodiphenyl sulfide, and $M_{\mathrm{n}}=5000-13000 \mathrm{~g} \mathrm{~mol}^{-1}$ for the polymers based on dihydroxydiphenyl ether and dithiodiphenyl ether. DSC reveals polymerization exotherms with maxima at $184-20{ }^{\circ} \mathrm{C}\left(\Delta H_{\mathrm{p}}=43-59 \mathrm{~kJ} \mathrm{~mol}^{-1}\right)$, which are believed to be due to isomerization of the cyanurate to the isocyanurate (activation energies span 159-195 $\mathrm{kJ} \mathrm{mol}^{-1}$ ). Molecular simulation shows that diphenylether and diphenylsulfide display very similar conformational energy surfaces and would therefore be expected to adopt similar conformations, but the diphenylsulfide offers less resistance to deformations that increase the proximity of the two phenyl rings and results in more resilient films.
\end{abstract}

(C) 2013 Society of Chemical Industry

Supporting information may be found in the online version of this article.

Keywords: terpoly(methoxy-cyanurate-thiocyanurate)s; thermal properties; isomerization

\section{INTRODUCTION}

We describe the terpolymerization of selected bisthiophenols and bisphenols with 2-methoxy-4,6-dichloro-s-triazine (MDCT) under phase transfer conditions to terpoly(methoxy-cyanuratethiocyanurate)s. The formation of linear polycyanurates from the reaction of chlorotriazines with alcohols in the presence of base dates back some 50 years, ${ }^{1}$ although early attempts to produce such polymers were of limited success because of the insoluble and intractable nature of the films due to uncontrolled crosslinking. The use of capped dichlorotriazines to prevent crosslinking and form linear polymers is the approach that has been adopted in this work and has already been found to be successful in previous studies. $^{2}$ Furthermore, we have adapted the method reported by Nakamura et al. ${ }^{3}$ in which polymerizations can be effected at comparatively low temperatures using a water-immiscible organic solvent in the presence of a cationic phase transfer catalyst (PTC), typically quaternary salts of organic amines. The present work builds on our previous studies involving polycyanurate homopolymers and copolymers by the controlled introduction of capped polythiocyanurates. The work was carried out in an attempt to improve the solubility of the resulting polymers in chlorinated solvents compared with the corresponding polythiocyanurate polymers described previously. ${ }^{4}$ Two series of polymers have been synthesized. One series starts with a copolymer based on equimolar amounts of thiodiphenol and dithiodiphenyl sulfide and the relative proportion of thiodiphenol in the polymerization mixture is gradually increased. An analogous series was prepared using dihydroxydiphenyl ether and dithiodiphenyl ether.

\section{EXPERIMENTAL}

\section{Materials}

Although this programme involved extensive preparative chemistry, in the interests of brevity the details for the preparation and characterization of the monomers have been deposited as supplementary information.

\footnotetext{
* Correspondence to: lan Hamerton, Department of Chemistry, Faculty of Engineering and Physical Sciences, University of Surrey, Guildford, Surrey GU2 7XH, UK. E-mail: i.hamerton@surrey.ac.uk

† Current address: Hexcel Composites Ltd, Duxford, Cambridge CB22 4QD, UK.

Department of Chemistry, Faculty of Engineering and Physical Sciences, University of Surrey, Guildford, Surrey, GU2 7XH, UK
} 
Table 1. Linear aromatic poly(methoxy-thiocyanurate-cyanurate)s

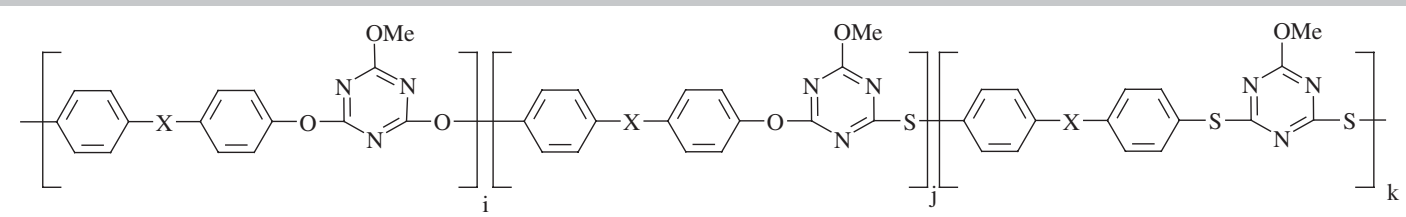

$\mathrm{X}=$-S- ---------> Series D

$X=-\mathrm{O}-$---------> Series E

\begin{tabular}{|c|c|c|c|c|}
\hline $\begin{array}{l}\text { Sample } \\
\text { designation }\end{array}$ & $\begin{array}{c}\text { Bisphenol } \\
\text { (molar ratio to } \mathrm{MDCT} \text { ) }\end{array}$ & $\begin{array}{c}\text { Bisthiophenol } \\
\text { (molar ratio to } \mathrm{MDCT} \text { ) }\end{array}$ & Polymer yield (\%) & Comments \\
\hline D1 & $\operatorname{TDP}(0.50)$ & DTPS $(0.50)$ & 80 & Resilient films (10-25 $\mu \mathrm{m})$ \\
\hline D2 & $\operatorname{TDP}(0.67)$ & DTPS (0.33) & 88 & Resilient films $(20-45 \mu \mathrm{m})$ \\
\hline D3 & $\operatorname{TDP}(0.75)$ & DTPS $(0.25)$ & 85 & Resilient films $(23-56 \mu \mathrm{m})$ \\
\hline D4 & $\operatorname{TDP}(0.33)$ & DTPS (0.67) & 89 & Resilient films (14-47 $\mu \mathrm{m})$ \\
\hline D5 & $\operatorname{TDP}(0.25)$ & DTPS (0.75) & 90 & Resilient films $(9-19 \mu \mathrm{m})$ \\
\hline E1 & DHPE (0.50) & DTPE (0.5) & 89 & Resilient films $(15-55 \mu \mathrm{m})$ \\
\hline E2 & DHPE (0.67) & DTPE (0.33) & 92 & Resilient films $(30-33 \mu \mathrm{m})$ \\
\hline E3 & DHPE (0.75) & DTPE (0.25) & 84 & Resilient films $(21-55 \mu \mathrm{m})$ \\
\hline E4 & DHPE (0.33) & DTPE (0.67) & 93 & Fragile films $(10-40 \mu \mathrm{m})$ \\
\hline E5 & DHPE (0.25) & DTPE (0.75) & 89 & Fragile films $(8-55 \mu \mathrm{m})$ \\
\hline
\end{tabular}

\section{Instruments and characterization}

Fourier transform infrared (FTIR) spectra were obtained using a Perkin Elmer 1750 FTIR spectrometer interfaced with a Perkin Elmer 7300 computer; a minimum of 24 scans was collected at a resolution of $2 \mathrm{~cm}^{-1}$. Materials that could be cast from solution were analysed directly as films; otherwise diffuse reflectance infrared spectroscopy (DRIFTS) was used. The spectral data are presented in absorbance units to allow easy comparison of the normal transmission spectra with DRIFTS data in Kubelka-Munk units. As the path length was not constant for different samples, no interpretation of the intensities has been made.

${ }^{1} \mathrm{H}$ and ${ }^{13} \mathrm{C}$ NMR spectra were primarily obtained at $298 \mathrm{~K}$ in $\mathrm{CDCl}_{3}$ using a Bruker EM $360 \mathrm{MHz}$ FT-NMR spectrometer equipped with a dual ${ }^{1} \mathrm{H} /{ }^{13} \mathrm{C}$ probe operating at $300 \mathrm{MHz}$ for ${ }^{1} \mathrm{H}$ and 75.5 $\mathrm{MHz}$ for ${ }^{13} \mathrm{C}$ respectively. In some instances the distortionless enhancement by polarization transfer method ${ }^{5}$ was used to assist in the assignment of the ${ }^{13} \mathrm{C}$ NMR spectra.

Gel permeation chromatography (GPC) was performed using a Waters $150 \mathrm{CV}$ equipped with a dual refractive index/viscometric detector. Waters $\mu$-Styragel-HT columns $\left(10^{6}, 10^{5}, 10^{4}, 10^{3}\right.$ A) were employed using $N, N^{\prime}$-dimethylacetamide (with $1 \%$ lithium chloride) as the eluent; in all instances the columns were maintained at $60{ }^{\circ} \mathrm{C}$. Calibration was carried out using polysaccharide (dextran) standards with molecular weights ranging from 5800 to $853000 \mathrm{~g} \mathrm{~mol}^{-1}$.

DSC was performed using a Shimadzu DSC-50 differential scanning calorimeter. Analyses were performed on samples $(5 \pm 1 \mathrm{mg})$ in nitrogen $\left(25-30 \mathrm{~cm}^{3} \mathrm{~min}^{-1}\right)$ in dynamic mode (10 K min ${ }^{-1}$ from ambient to $490^{\circ} \mathrm{C}$ ). A two-point calibration was carried out using high purity (>99.99\%) indium and zinc wire. Glass transition temperature $\left(T_{\mathrm{g}}\right)$ values were determined according to ASTM D3418 ${ }^{6}$ by heating the sample to above its $T_{g}$, holding it at that temperature to reduce the effect of previous thermal treatments, cooling below $T_{\mathrm{g}}$ and then reheating through the $T_{\mathrm{g}}$ at $20 \mathrm{~K} \mathrm{~min}^{-1}$.

TGA was performed using a Shimadzu TGA-50 thermogravimetric analyser. Analyses were initially performed on samples ( $6 \pm 1$ $\mathrm{mg})$ in nitrogen $\left(50 \mathrm{~cm}^{3} \mathrm{~min}^{-1}\right)$ and also air $\left(50 \mathrm{~cm}^{3} \mathrm{~min}^{-1}\right)$ in dynamic mode $\left(20 \mathrm{~K} \mathrm{~min}^{-1}\right.$ from ambient to $490^{\circ} \mathrm{C}$ ) and isothermal mode (in which the sample was ramped rapidly at $99 \mathrm{~K} \mathrm{~min}^{-1}$ to the analysis temperature before being maintained for the desired time). A two-point calibration was carried out using high purity (>99.99\%) indium and zinc wire.

\section{General polymerization method}

The reaction mixtures comprised a bisphenol (thiodiphenol or dihydroxydiphenyl ether (DHPE)), a bisthiophenol (dithiodiphenyl ether (DTPE) and dithiodiphenyl sulfide), MDCT and cetrimide (cetrimonium bromide, $6 \mathrm{~mol} \%$ ). Table 1 shows the stoichiometry employed in the preparation of the polymers. All polymerizations were carried out in dichloromethane (total reaction volume $125 \mathrm{~cm}^{3}$; the phase:volume ratio (PVR) of the reaction mixture, organic:aqueous, was 0.25$)$ at $30{ }^{\circ} \mathrm{C}$ on an 0.01 molar scale. A solution of sodium hydroxide $\left(0.2 \mathrm{~mol} \mathrm{~L}^{-1}\right)$ in water $\left(100 \mathrm{~cm}^{3}\right)$ was prepared in a three-necked $250 \mathrm{~cm}^{3}$ round-bottomed flask and degassed (30 $\mathrm{min}$ ) with a strong flow of nitrogen. The reagents were added to the degassed solution under nitrogen (see Table 1 for designations used for the polymers in this paper and specific reagent quantities). The organic phase was rapidly added to the aqueous phase (with vigorous magnetic stirring at $600 \mathrm{rpm}$ ) to yield conditions suitable for interfacial polymerization. The reaction mixture was raised to the desired polymerization temperature $\left(30{ }^{\circ} \mathrm{C}\right.$ ) before being maintained (under a positive pressure nitrogen blanket) isothermally using a thermostatted oil bath. 

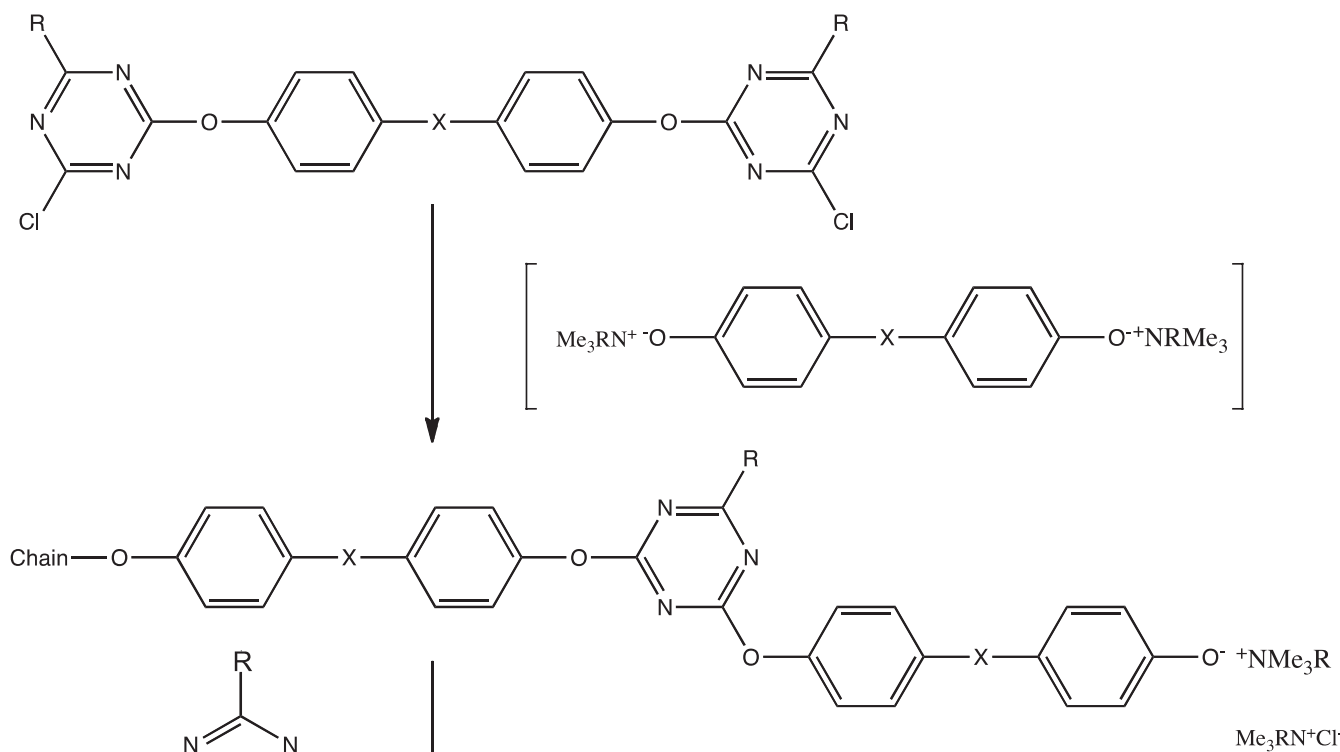<smiles>Clc1ncnc(Cl)n1</smiles><smiles>[X]c1ccc(Oc2nc([R])nc(Oc3ccc(Oc4nc([X])nc(Cl)n4)cc3)n2)cc1</smiles>

Scheme 1. Propagation reaction for linear polycyanurates and polythiocyanurates under phase transfer catalysis conditions.

After $18 \mathrm{~h}$, stirring was ceased and the emulsion was allowed to settle before the addition of saturated sodium hydrogen carbonate solution or brine $\left(25-50 \mathrm{~cm}^{3}\right)$ to break the emulsion. The organic phase was removed and the aqueous phase was extracted with fresh dichloromethane $\left(2 \times 25 \mathrm{~cm}^{3}\right)$. The organic extracts were then combined and dried over magnesium sulfate before the solvent was removed under reduced pressure. The crude polymer thus produced was purified by dissolution in fresh solvent ( 50 $\mathrm{cm}^{3}$ ) and precipitated into a suitable non-solvent (hexane, 200 $\left.\mathrm{cm}^{3}\right)$. The precipitates were then filtered and dried in vacuo $\left(80^{\circ} \mathrm{C}\right.$, $24 \mathrm{~h}$ ) before analysis (elemental analyses were conducted for the polymers and these are given in Table S1).

\section{General simulation method}

The program Cerius ${ }^{2}$ v 2 (Accelrys Inc.) using a Dell PC was employed to generate models of the polycyanurate structural repeat units using the amorphous builder module. All structures were fully minimized using conjugate gradients ${ }^{7}$ until convergence was achieved. When applicable, a stochastic conformational search using the Universal Force Field (UFF) ${ }^{8,9}$ molecular mechanics parameter set was carried out to identify the lowest energy conformation. Electronic properties for the structural repeat units were calculated using MOPAC $6^{10}$ with geometry optimization, using restricted Hartree Fock with the PM3 Hamiltonian.

\section{RESULTS AND DISCUSSION} phase transfer conditions using cetrimide as the PTC. Initially, the polymerization was performed using a reported method ${ }^{11}$ in which a PVR of 1 was used and the PTC (6 mol\%) was added, but later studies suggested that a PVR of $0.25^{12}$ yielded a high molecular weight product and this was employed in this work to achieve a similar result. The deprotonation of the aromatic thiols required a stronger base than was required for the formation of the corresponding bisphenoxides ${ }^{13}$ and the time required to achieve dissolution in the aqueous phases was longer; in some cases turbid solutions resulted. All reactions were carried out under nitrogen to prevent termination by oxidation to a quinoid-type structure. Alternatively termination can occur via hydrolysis of a chlorotriazine moiety from the chain or from the formation of a ring. ${ }^{7}$ The initial step of the polymerization involves the formation of a PTC-phenylsulfide adduct (Scheme 1), followed directly by chain initiation, and the first stage of chain growth occurs by sequential addition of one equivalent of the 2:1 PTC-bisphenylsulfide adduct. The result is a phenylsulfide-terminated chain that is reactive towards the chlorotriazine although chain addition is also possible between growing oligomeric chains bearing groups of complementary reactivity (i.e. a phenylsulfide-terminated oligomer may undergo co-reaction with another bearing a terminal chlorotriazine moiety); the latter step growth mechanism yields significantly larger increases in molecular weight than the former. All polymers exhibited lower than theoretical levels of nitrogen (Tables S1 and S2), and these deviations almost certainly stem from incomplete reaction of the monomer and residual solvent. 


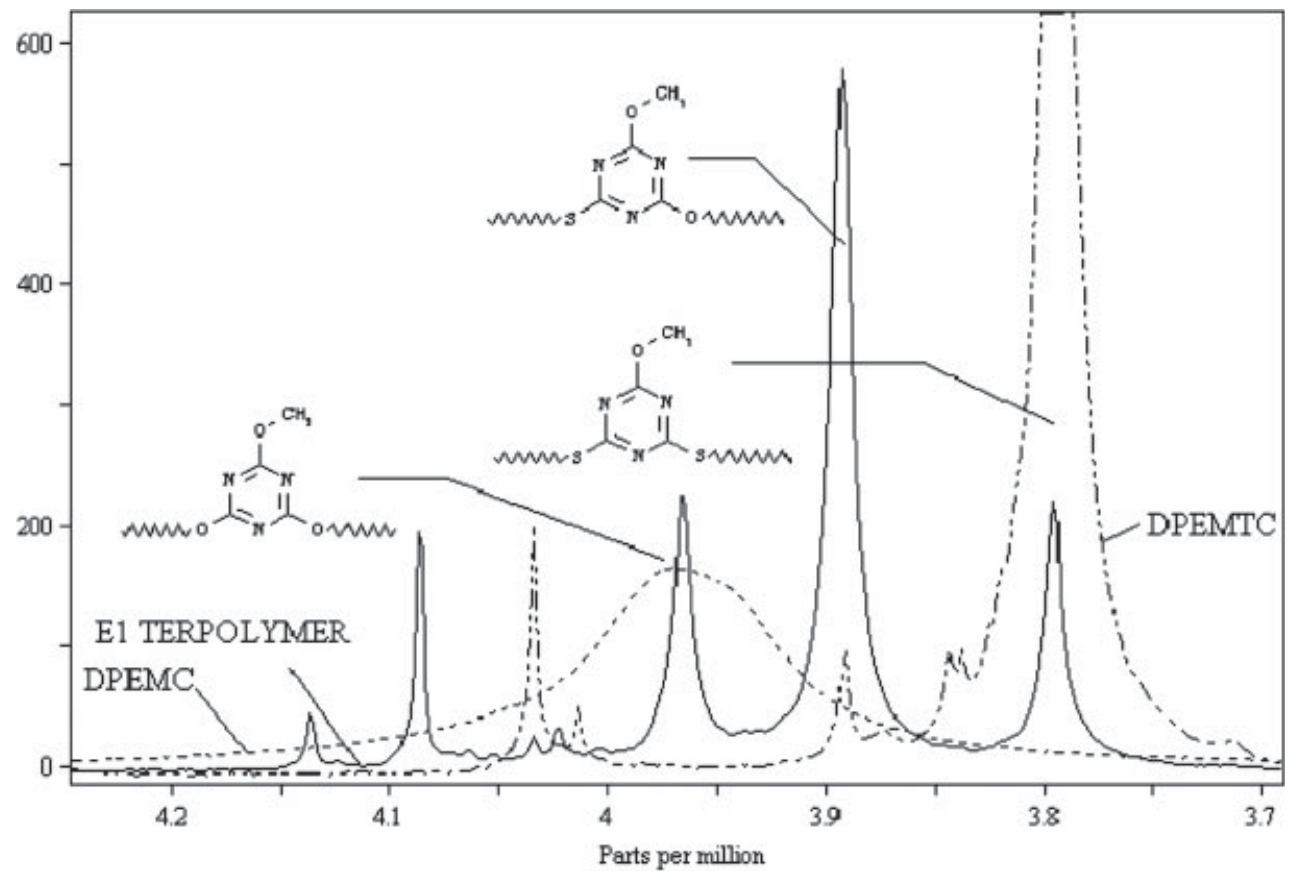

Figure 1. ${ }^{1} \mathrm{H}$ NMR spectra of terpoly(methoxy-cyanurate-thiocyanurate)s derived from commercial bisphenols.

Table 2. Molecular weight averages for linear aromatic poly (methoxy-thiocyanurate-cyanurate)s

\begin{tabular}{lccccccccc|} 
& \multicolumn{1}{c}{ Molecular weight averages (Da) } & & & \\
\cline { 2 - 7 } Sample & $M_{\mathrm{n}}$ & $M_{\mathrm{p}}$ & $M_{\mathrm{w}}$ & $M_{z}$ & $M_{z+1}$ & $M_{\mathrm{w}} / M_{\mathrm{n}}$ & $x_{\mathrm{n}}$ & $p$ \\
\hline D1 & 13000 & 32000 & 37000 & 69000 & 101000 & 2.85 & 76 & 0.986 \\
D2 & 17000 & 46000 & 52000 & 102000 & 154000 & 3.06 & 101 & 0.991 \\
D3 & 8000 & 28000 & 33000 & 72000 & 114000 & 4.12 & 48 & 0.979 \\
E1 & 7000 & 17000 & 26000 & 62000 & 103000 & 3.71 & 43 & 0.977 \\
E2 & 5000 & 14000 & 22000 & 57000 & 96000 & 4.40 & 31 & 0.968 \\
E3 & 13000 & 29000 & 38000 & 77000 & 119000 & 2.92 & 81 & 0.988 \\
E4 & 5000 & 14000 & 21000 & 54000 & 93000 & 4.20 & 30 & 0.967 \\
\hline
\end{tabular}

\section{Spectroscopic characterization of the polymers}

All the linear polymers in the series (Table 1) exhibited similar vibrational spectra and the majority of the bands are attributable to characteristic structural motifs. All the polymers exhibit a strong band between 1220 and $1190 \mathrm{~cm}^{-1}$ and the symmetrical mode in which the $\mathrm{C}-\mathrm{O}$ stretches are coupled to the symmetrical triazine ring breathing motion appears as a band at $1390 \mathrm{~cm}^{-1}$. Padgett and Hamner ${ }^{14}$ postulated that the band close to $1220 \mathrm{~cm}^{-1}$, which is common to all the tri-substituted cyanurates, was due to a second mode involving a $\mathrm{C}-\mathrm{O}$ stretch correlated to motion of the substituents around the cyanurate system. ${ }^{1} \mathrm{H}$ and ${ }^{13} \mathrm{C}$ NMR comparison was made directly against data obtained for the corresponding homopolymers ${ }^{4,8}$ and ${ }^{1} \mathrm{H}$ NMR data are in good agreement with those reported in the literature for other linear polycyanurates with the methoxy protons falling between 3.94 and 3.98 ppm (Fig. 1). ${ }^{15-17}$

The ${ }^{1} \mathrm{H}$ NMR spectra for D1 and E1 share some characteristics: a complex multiplet in the aromatic region resulting from the overlaid peaks observed in the spectra of the copolymers with additional aromatic peaks resulting from the terpolymer. The ${ }^{1} \mathrm{H}$ NMR spectrum of D1 supports the formation of a random
Table 3. Thermal stability of linear aromatic poly(methoxythiocyanurate-cyanurate)s in nitrogen (heating rate $20 \mathrm{~K} \mathrm{~min}^{-1}$, flow rate $50 \mathrm{~cm}^{3} \mathrm{~min}^{-1}$ )

\begin{tabular}{|lcccccccc} 
Polymer $\left({ }^{\circ} \mathrm{C}\right)^{\mathrm{a}}$ & $\begin{array}{c}T_{2 \%} \\
\left({ }^{\circ} \mathrm{C}\right)\end{array}$ & $\begin{array}{c}T_{3 \%} \\
\left({ }^{\circ} \mathrm{C}\right)\end{array}$ & $\begin{array}{c}T_{5 \%} \\
\left({ }^{\circ} \mathrm{C}\right)\end{array}$ & $\begin{array}{c}T_{10 \%} \\
\left({ }^{\circ} \mathrm{C}\right)\end{array}$ & $\begin{array}{c}T_{20 \%} \\
\left({ }^{\circ} \mathrm{C}\right)\end{array}$ & $\begin{array}{c}T_{\max } \\
\left({ }^{\circ} \mathrm{C}\right)^{\mathrm{b}}\end{array}$ & $\begin{array}{c}\% \text { Residue } \\
\text { at } 490{ }^{\circ} \mathrm{C}\end{array}$ \\
\hline D1 & 290 & 333 & 345 & 356 & 368 & 382 & 377 & 55 \\
D2 & 326 & 348 & 357 & 366 & 377 & 391 & 387 & 54 \\
D3 & 158 & 299 & 342 & 359 & 372 & 387 & 380 & 53 \\
D4 & 326 & 343 & 350 & 358 & 368 & 384 & 372 & 60 \\
D5 & 333 & 346 & 351 & 358 & 367 & 384 & 372 & 61 \\
E1 & 182 & 290 & 346 & 363 & 378 & 390 & 385 & 54 \\
E2 & 234 & 272 & 306 & 352 & 372 & 387 & 389 & 50 \\
E3 & 160 & 274 & 336 & 368 & 384 & 397 & 397 & 51 \\
E4 & 224 & 301 & 325 & 341 & 357 & 375 & 369 & 54 \\
E5 & 171 & 271 & 337 & 356 & 370 & 380 & 378 & 57 \\
\hline
\end{tabular}

${ }^{a} T_{x \%}$ is the temperature at which $x \%$ weight loss is observed.

${ }^{\mathrm{b}}$ Temperature of maximum weight loss determined from the first derivative of the weight loss curve.

copolymer: three different methoxy signals are observed (3.94, 3.88 and $3.79 \mathrm{ppm}$ ) corresponding to the different repeat units (denoted $\mathrm{i}, \mathrm{j}$ and $\mathrm{k}$ in Table $\mathrm{S} 1$ ). The ratios are approximately $1_{\mathrm{i}}: 2_{\mathrm{j}}: 1_{\mathrm{k}}$ which would be expected for the random polymerization of two equally reactive diols with MDCT. The incorporation of thiocyanurates increases the difference in chemical shift between the aromatic protons ortho and meta to the triazine ring as well as reducing the chain relaxation time. This is in good agreement with published substituent effects on the proton chemical shifts of substituted benzenes and with literature values for linear ${ }^{3}$ and crosslinked ${ }^{18,19}$ polycyanurates. The thioether moiety shifts the signal of the ortho protons approximately $0.4 \mathrm{ppm}$ downfield. The assignment of ${ }^{13} \mathrm{C}$ chemical shifts for $\mathrm{E} 1$ are less conclusive (with some broadening apparent) but provide some supporting 

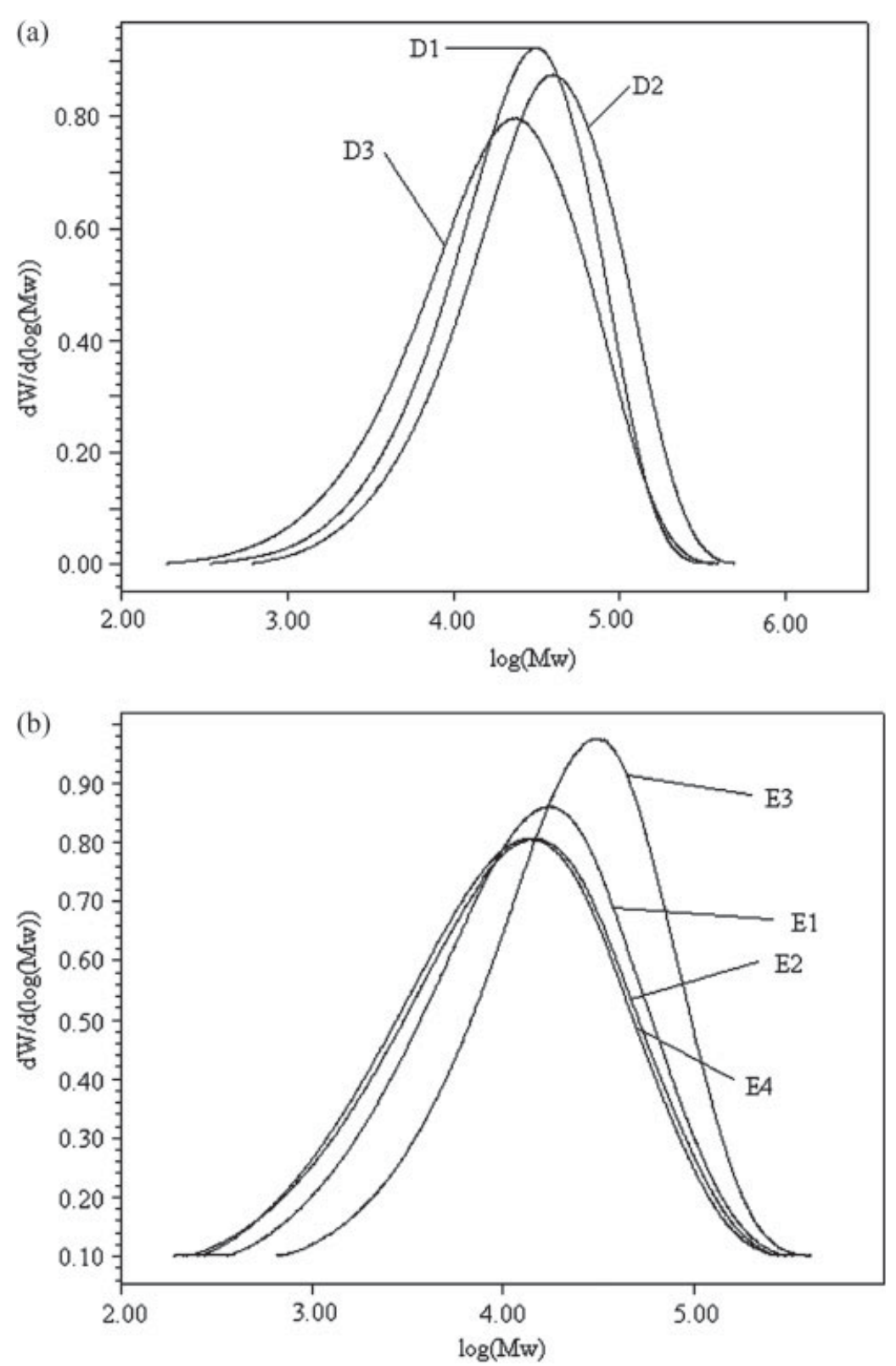

Figure 2. Molecular weight data for linear terpoly(methoxy-cyanurate-thiocyanurate)s: (a) D series; (b) E series (note the data are plotted on different scales).

evidence for the formation of a random copolymer. Three distinct signals are visible close to $55 \mathrm{ppm}$, which correspond to three different methoxy environments.

E1 is the polymeric product formed from the copolymerization of a 50/50 mixture of DHPE and DTPE with MDCT and, as such, it should contain three different triazine units as depicted in Table 1. Two of the signals correspond directly to those observed for copoly(diphenyl ether-methoxy-cyanurate) (denoted DPEMC) (3.89 ppm) and copoly(diphenyl ether-methoxy-thiocyanurate) (denoted DPEMTC) (3.79 ppm) and the third weaker signal, intermediate between the two, appears at $4.08 \mathrm{ppm}$. This represents the methoxy substituent attached to a triazine ring bearing a phenoxy and a thiophenoxy moiety; the ratio of integrals in E1 (following Fourier deconvolution using GRAMS software, ADEPT Scientific) is also approximately $1_{\mathrm{i}}: 2_{\mathrm{j}}: 1_{\mathrm{k}}$ consistent with a random terpolymer.

\section{The dependence of molecular weight distribution on molecular structure}

Although not all the terpolymers were soluble in dimethylacetamide and thus could not be analysed by GPC using our instrumentation, data for samples D1-D3 and E1-E3 are presented (Table 2). As all the terpolymers prepared in series $D$ and E could be cast as films it is presumed that samples D4, D5 and E5 were also of moderate to high molecular weight. A stoichiometrically weighted average of the two repeat units was used in conjunction with $M_{\mathrm{n}}$ in the Carothers' equation ${ }^{20}$ for an A-A/B-B polymer to calculate the number-average degree of polymerization $\left(x_{n}\right)$ and the extent of monomer conversion $(p)$ for each material. The breadth of the distributions (Fig 2) even in the samples with higher molecular weight (D1, D2, E3) suggests that at high degrees of conversion the reaction is being terminated by either diffusion control or hydrolysis of the active terminal groups. 

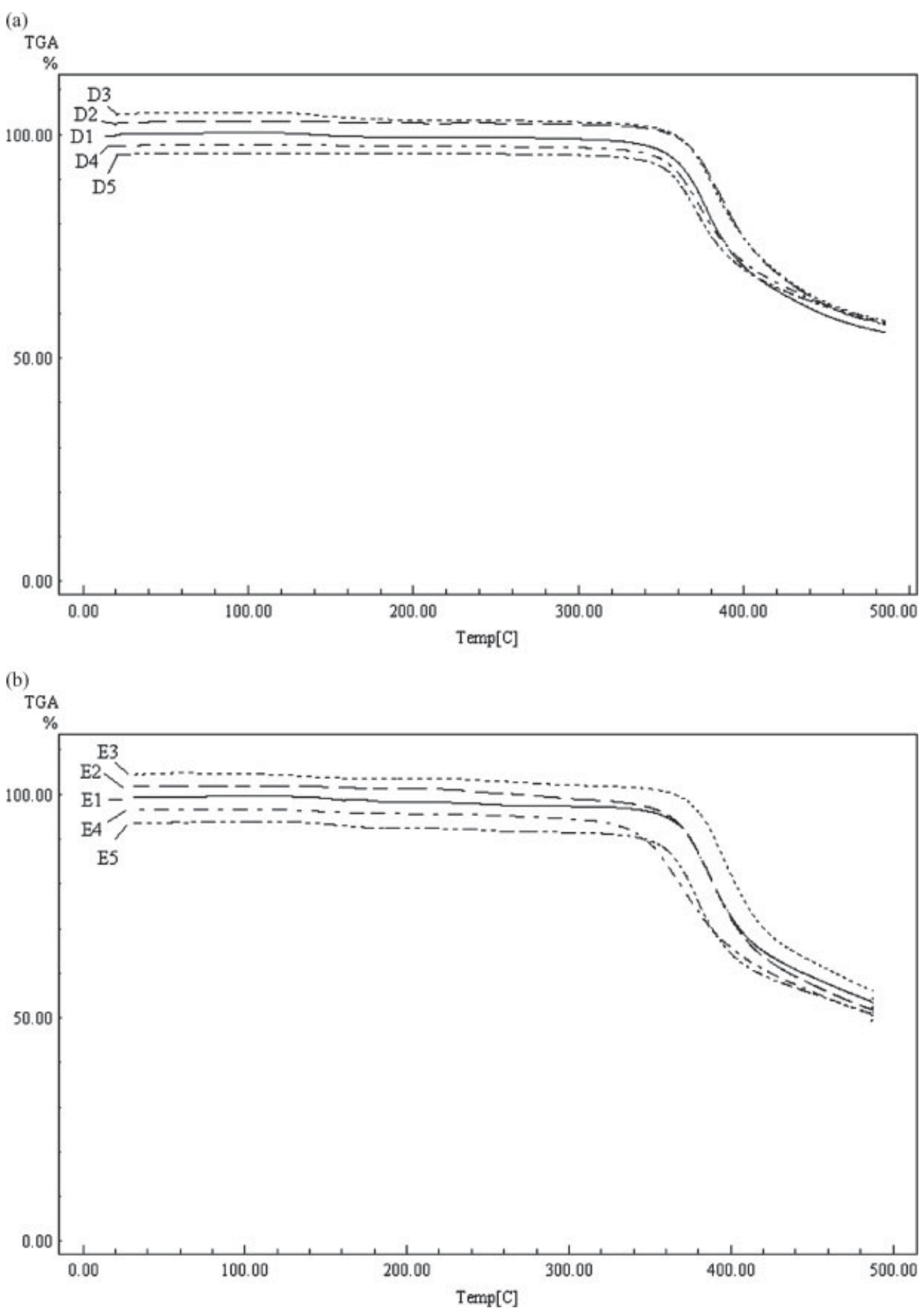

Figure 3. TGA curves for terpoly(methoxy-cyanurate-thiocyanurate)s under nitrogen (heating rate $20 \mathrm{~K} \mathrm{~min}^{-1}$, flow rate $50 \mathrm{~cm}^{3} \mathrm{~min}^{-1}$ ).

The polymerization is an example of a step growth addition mechanism, but this is only truly the case once all the bisthiol monomer has been carried across into the organic phase by the PTC. All of the polymers were soluble in dichloromethane or chloroform to give viscous solutions, which could be readily cast as films that could be released from glass plates for analysis. The elemental compositions of the polymers (Tables S1 and S2) were in good agreement with the degree of conversion calculated from the GPC data. The sample E1 which was heated to $300{ }^{\circ} \mathrm{C}$ in air (E1ANN) did not show any change in elemental composition beyond what might be expected for elimination of a very small amount of residual solvent.

\section{Influence of polymer structure on thermal and thermo-oxidative stability}

All the polymers were analysed for their thermal stability in nitrogen by dynamic TGA. The analyses were carried out between ambient temperature and $490{ }^{\circ} \mathrm{C}$ at an atmospheric flow rate of $50 \mathrm{~cm}^{3} \mathrm{~min}^{-1}$ and a heating rate of $20 \mathrm{~K} \mathrm{~min}^{-1}$. The TGA data are summarized in Table 3 and the TGA curves for selected polymers are shown in Fig. 3. All the samples displayed similar stability in nitrogen and the onsets of decomposition (in excess of $350{ }^{\circ} \mathrm{C}$ ) were of comparable magnitude to those observed for poly(methoxy-cyanurate)s $s^{8}$ and poly(ethoxy-cyanurate)s, $s^{7,21}$ 
Table 4. Thermal events for linear aromatic poly(methoxythiocyanurate-cyanurate)s as determined by DSC

\begin{tabular}{|c|c|c|c|c|c|c|c|c|c|}
\hline \multirow[b]{2}{*}{ Polymer ${ }^{T}$} & \multirow[b]{2}{*}{$\begin{array}{l}T_{\mathrm{g} 1} \\
\left({ }^{\circ} \mathrm{C}\right)\end{array}$} & \multirow[b]{2}{*}{$\begin{array}{l}T_{\text {ip }} \\
\left({ }^{\circ} \mathrm{C}\right)\end{array}$} & \multirow[b]{2}{*}{$\begin{array}{l}T^{\prime}{ }_{\text {ip }} \\
\left({ }^{\circ} \mathrm{C}\right)\end{array}$} & \multirow[b]{2}{*}{$\begin{array}{l}T_{\mathrm{p}} \\
\left({ }^{\circ} \mathrm{C}\right)\end{array}$} & \multirow[b]{2}{*}{$\begin{array}{l}T_{\text {ep }}^{\prime} \\
\left({ }^{\circ} \mathrm{C}\right)\end{array}$} & \multirow[b]{2}{*}{$\begin{array}{l}T_{\mathrm{ep}} \\
\left({ }^{\circ} \mathrm{C}\right)\end{array}$} & \multicolumn{2}{|c|}{$\Delta H_{\mathrm{p}}$} & \multirow[b]{2}{*}{$\begin{array}{l}T_{\mathrm{g} 2} \\
\left({ }^{\circ} \mathrm{C}\right)\end{array}$} \\
\hline & & & & & & & $\mathrm{Jg}^{-1}$ & $\begin{array}{c}\mathrm{kJ} \\
\mathrm{mol}^{-1}\end{array}$ & \\
\hline D1 & 125 & 143 & 165 & 201 & 233 & 254 & 150 & 51.2 & 183 \\
\hline D2 & 123 & 144 & 162 & 198 & 235 & 244 & 150 & 0.4 & 190 \\
\hline D3 & 105 & 144 & 164 & 196 & 233 & 246 & 15 & & 190 \\
\hline D4 & 108 & 140 & 168 & 207 & 236 & 246 & 14 & 年 & 179 \\
\hline D5 & 112 & 144 & 169 & 207 & 235 & 256 & 14 & 48 & 173 \\
\hline E1 & 122 & 139 & 157 & 192 & 228 & 235 & 180 & 58.6 & 187 \\
\hline E2 & - & 142 & 154 & 184 & 226 & 228 & 140 & 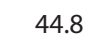 & 172 \\
\hline E3 & - & 146 & 159 & 186 & 233 & 235 & 150 & 47.6 & 198 \\
\hline E4 & 131 & 140 & 168 & 207 & 236 & 246 & 130 & 3.0 & 174 \\
\hline E5 & 107 & 142 & 162 & 193 & 224 & 246 & 130 & 43.3 & 170 \\
\hline
\end{tabular}

$T_{\mathrm{g} 1}$, possible glass transition of polymer determined using a heating rate of $10 \mathrm{~K} \mathrm{~min}^{-1} ; T_{\mathrm{ip}}$, observed onset of polymerization; $T^{\prime}{ }_{\mathrm{ip}}$, extrapolated onset of polymerization (from triangulation of the apex of the polymerization exotherm); $T_{\mathrm{p}}$, temperature of the exothermic peak maximum; $T^{\prime}$ ep, extrapolated end of polymerization (from triangulation of the apex of the polymerization exotherm); $T_{\text {ep }}$, observed end of polymerization; $\Delta H_{\mathrm{p}}$, enthalpy of exothermic peak; $T_{\mathrm{g} 2}$, glass transition temperature of polymer determined using a heating rate of $20 \mathrm{~K} \mathrm{~min}^{-1}$.

with the primary differences being that the poly(methoxythiocyanurate)s exhibit a slightly higher char yield at $490{ }^{\circ} \mathrm{C}$ (average char yield 62\%). The initial phase of the degradation $\left(300-400{ }^{\circ} \mathrm{C}\right.$, maximum $375^{\circ} \mathrm{C}$ ) precedes a significant mass loss, in a higher temperature regime (maximum $550{ }^{\circ} \mathrm{C}$ ). This major mass loss is observed in all polycyanurates and has been found to be due to decyclization of the triazine ring, liberating volatile decomposition products. Walters and colleagues ${ }^{22}$ attributed this step to decyclization of the cyanurate to the corresponding isocyanurate. The latter underwent further hydrolysis to yield carbamic acid that decomposes spontaneously to form carbon dioxide and ammonia at temperatures above $200{ }^{\circ} \mathrm{C}$. It is well known that cyanates undergo slow reaction with atmospheric moisture to form carbamates, with similar results at elevated temperatures. ${ }^{23}$ The terpoly(methoxy-cyanurate-thiocyanurate)s do not exhibit the $1 \%-2 \%$ weight loss at low temperatures which are characteristic of poly(methoxy-cyanurate)s prepared using the same method, suggesting that the polymers reported here do not contain significant amounts of residual monomer.

\section{Comparison of kinetics of thermal conversion of terpoly(methoxy-cyanurate-thiocyanurate)s}

The heating programme heat cycle 1 from $25-300{ }^{\circ} \mathrm{C}$ at $10 \mathrm{~K}$ $\mathrm{min}^{-1}$; cool $300-70{ }^{\circ} \mathrm{C}$ at $-10 \mathrm{~K} \mathrm{~min}^{-1}$ and hold for $10 \mathrm{~min}$; heat cycle 2 from $70-300{ }^{\circ} \mathrm{C}$ at $20 \mathrm{~K} \mathrm{~min}^{-1}$ was used for all samples. The foregoing analysis using TGA had revealed no significant decomposition at $300{ }^{\circ} \mathrm{C}$ under nitrogen. On the first heating cycle two thermal events were commonly evident: a very weak endotherm (not observed in E2 and E3) was possibly a glass transition (modulated DSC was not available to us at this time) and a prominent exotherm around $180-200^{\circ} \mathrm{C}$; the temperatures corresponding to these are denoted $T_{\mathrm{g} 1}$ and $T_{\mathrm{p}}$ respectively (Table 4). The enthalpy of the polymerization exotherm, $\Delta H_{p}$, was calculated using a standard method ${ }^{24}$ and is expressed in
Table 5. Kinetic parameters for the exotherm observed in DSC analysis of linear aromatic poly(methoxy-thiocyanurate-cyanurate)s

\begin{tabular}{lccccc|} 
Polymer & $\begin{array}{c}\text { Onset } \\
\text { temperature } \\
\left({ }^{\circ} \mathrm{C}\right)\end{array}$ & $\begin{array}{c}\text { Final } \\
\text { temperature } \\
\left({ }^{\circ} \mathrm{C}\right)\end{array}$ & $\begin{array}{c}\text { Linear } \\
\text { range } \\
\text { (corresponding } \\
\text { to } \Delta H, \%)\end{array}$ & $\begin{array}{c}E_{\mathrm{a}} \\
(\mathrm{kJ}\end{array}$ & $\begin{array}{c}\left.\mathrm{mol}^{-1}\right) \\
\text { D1 }\end{array}$ \\
D2 & 158 & 225 & 95 & 0.991 & 179 \\
D3 & 155 & 224 & 95 & 0.996 & 179 \\
D4 & 155 & 222 & 95 & 0.997 & 184 \\
D5 & 154 & 218 & 92 & 0.994 & 165 \\
E1 & 150 & 215 & 78 & 0.996 & 165 \\
E2 & 157 & 220 & 96 & 0.994 & 189 \\
E3 & 156 & 215 & 96 & 0.995 & 198 \\
E4 & 159 & 218 & 93 & 0.996 & 181 \\
E5 & 154 & 211 & 71 & 0.996 & 159 \\
& 162 & 234 & 96 & 0.998 & 195 \\
\hline
\end{tabular}

terms of $\mathrm{J} \mathrm{g}^{-1}$ and $\mathrm{kJ} \mathrm{mol}^{-1}$ (with respect to the structural repeat unit of the polymer chain). On the second heating cycle all samples exhibited an increase in heat capacity, consistent with the observation of a glass transition temperature (denoted $T_{\mathrm{g} 2}$ ), between the onset and endset temperatures of the exotherm in the first heating cycle. The exotherms are generally very similar for all the samples analysed in this work and also to data reported by other workers for poly(methoxy-cyanurate)s subjected to similar heating cycles. ${ }^{6,9,10,25-27}$ Although Braun and Ziser, ${ }^{12,21}$ who worked extensively with 2,4-dichloro-6-ethoxytriazine, did not report exothermic behaviour in their samples, we have observed similar behaviour in poly(methoxy-cyanurate)s. ${ }^{8}$ All of the samples undergo very similar exothermic changes. The onsets of the exotherms are typically in the region of $140{ }^{\circ} \mathrm{C}$ which is comparable to the onset temperatures previously observed for poly(thiocyanurate)s. ${ }^{4}$ The breadth of the exotherm is markedly greater in the polymers within series $E$ (containing exclusively cyanurate linkages along the chain), with an apparent high temperature shoulder in E3.

The conformational plots of the ether and thioether linkages in cyanurates and thiocyanurates are presented below and suggest that the two structural units differ in their flexibility. According to how many methoxy-triazine units have undergone isomerization, differences in the glass transitions of the materials determined during the second DSC run may be expected between these terpolymers and their corresponding parent systems. The DSC curves obtained on the second cycle to determine the glass transition temperatures of the samples in series $D$ and $E$ can be seen in Figs. $4 \mathrm{~b}$ and $5 \mathrm{~b}$ respectively. The exothermic peaks observed in the DSC thermograms were analysed using the method of Sun et al. $^{28}$ on the assumption that a single first-order process was responsible for the exotherm. The method is based on the fact that the kinetics of any process which results in the conversion of a material from one form to another can be described by

$$
\frac{1}{A}\left(\frac{\partial H}{\partial t}\right)_{T}-k_{0}\left[1-\frac{A_{t}}{A}\right]^{n} e^{-E a / R T}
$$

where $A$ is the integral under the DSC exotherm, $A_{t}$ is the integral under the DSC curve from $T_{\text {ip }}$ to $T, E_{\mathrm{a}}$ is the activation energy, $R=$ $8.31451 \mathrm{~J} \mathrm{~K}^{-1} \mathrm{~mol}^{-1}$ and $n$ is the order of the reaction. 

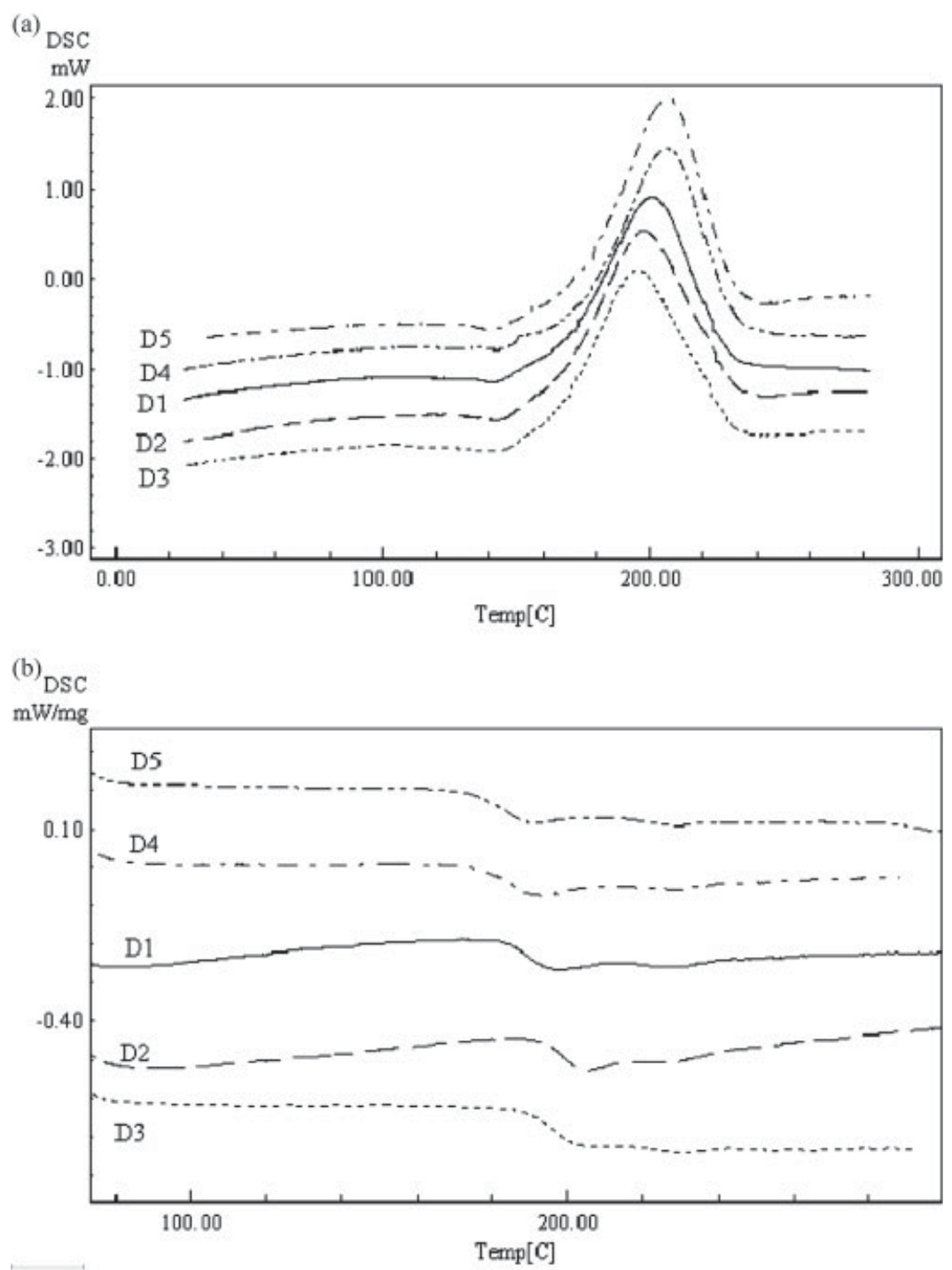

Figure 4. (a) DSC curves for terpoly(methoxy-cyanurate-thiocyanurate)s of thiodiphenol and dithiodiphenyl sulfide (heating rate $10 \mathrm{~K} \mathrm{~min}{ }^{-1}$ ) and (b) DSC rescan curves (heating rate $20 \mathrm{~K} \mathrm{~min}^{-1}$ ). Flow rate under nitrogen $30 \mathrm{~cm}^{3} \mathrm{~min}^{-1}$.

As $A, A_{t}$ and $\partial H / \partial t$ can be obtained from the DSC curve it is possible to calculate a value for $k(T)$ for each temperature. If the reaction is first order (i.e. $n=1$ ), it follows that a plot of $\ln k(T)$ against 1/T should give a straight line whose gradient will yield $E_{\mathrm{a}}$ and $k_{0}$ for the overall process. The temperature range over which the data fitted the first-order kinetic model for each polymer and the quality of fit $\left(R^{2}\right)$ are summarized in Table 5 (deviation from linearity is observed at the extremes of the temperature range). It is clear that the model applies very well $\left(0.991 \leq r^{2} \leq 0.998\right)$ over a wide temperature range corresponding to around $92 \%-96 \%$ of the total observed exotherm for the thermal event. There are two notable exceptions (D5 and E4) wherein the temperature range over which the plots are linear are somewhat narrower (78\% and $71 \%$ respectively). Aside from the greater proportion of bisthiol (75 mol\%) used in each case, there is no obvious reason for the anomaly.

\section{Molecular simulation to examine the effect of polymer chain flexibility}

Molecular simulation was employed to examine the comparative flexibility and rotational freedom of the bridges in the backbone.
The torsional barriers to rotation for the backbone linkages of the polymer repeat units depicted in Fig. 6 were investigated using a grid search method employing the UFF force field and charges assigned by the charge equilibration method. The grid search varies the two torsions (designated $\phi$ and $\psi$ ) in a nested cycle and calculates the energy of each conformation generated. The molecule was allowed to minimize after each step of the grid search but the torsions $\phi$ and $\psi$ were constrained by an energy barrier of $1000 \mathrm{kcal} \mathrm{mol}^{-1}$. Contour maps of the potential energy surfaces determined in this way are also shown in Fig. 6 ( $\phi$ and $\psi$ are equivalent in these four representative molecules and so all of the potential energy surfaces have axes of symmetry through $\psi=\phi$ and $\psi=-\phi$ ). Each conformational plot was analysed to determine average energetic barriers to motion. The major energetic barriers considered are illustrated (in white) in Fig. $6(a)$. The depths of the potential energy wells were measured by subtracting the potential energy of the conformer at the base of the well (the white areas) from the potential energy of the conformer at the saddle point between two potential energy wells (marked as white circles). 
(a)

DSC

$\mathrm{mW} / \mathrm{mg}$

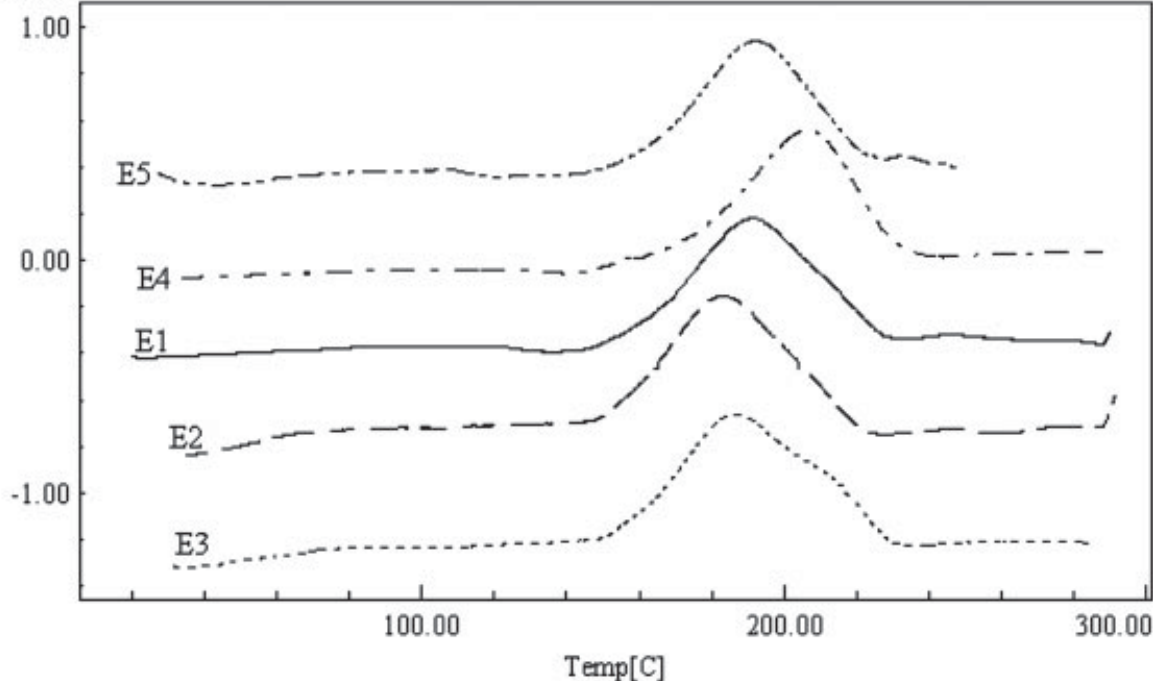

(b)

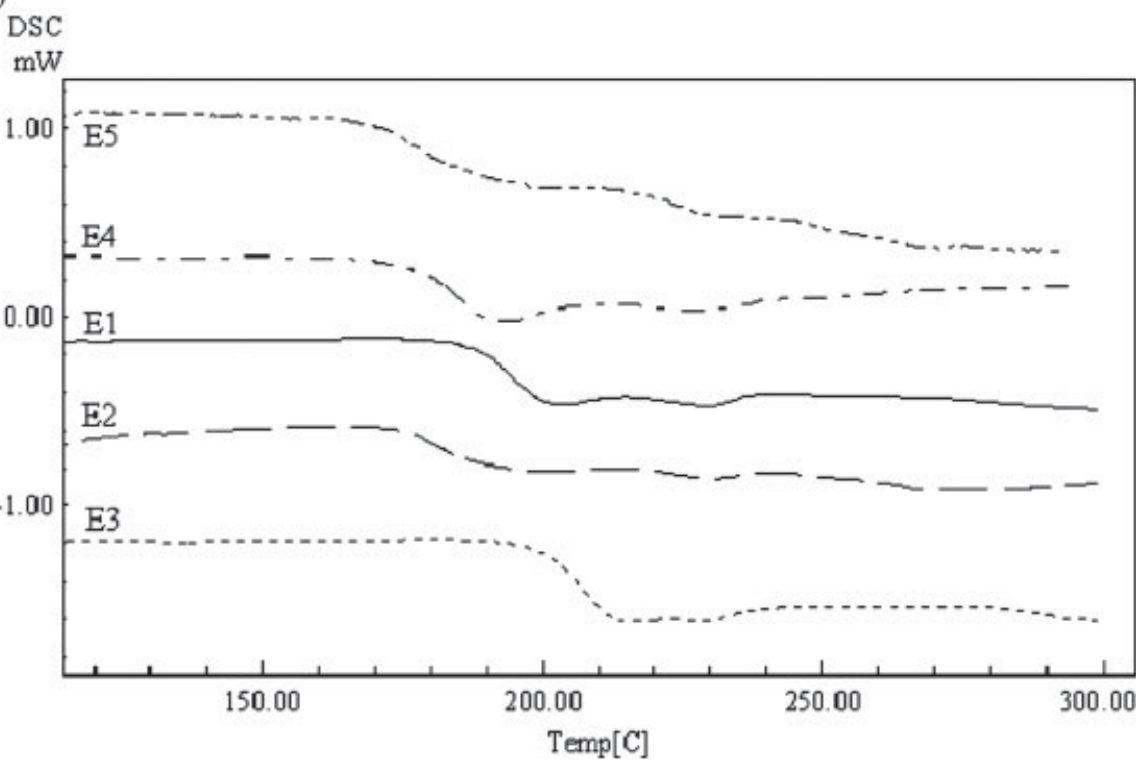

Figure 5. (a) DSC curves for terpoly(methoxy-cyanurate-thiocyanurate)s of DHPE and DTPE (heating rate $10 \mathrm{~K} \mathrm{~min}^{-1}$ ) and (b) DSC rescan curves (heating rate $20 \mathrm{~K} \mathrm{~min}^{-1}$ ). Flow rate under nitrogen $30 \mathrm{~cm}^{3} \mathrm{~min}^{-1}$.

In this way it was possible to get an impression of the flexibility of a given linkage and the conformational space it explores. The barriers listed for each unit include the highest barrier to rotation (marked A on Fig. 6(a)); the barrier to rotation which arises from hopping between minima by increasing $\psi$ and $\phi$ in the same sense is marked $B$, and the barrier to rotation if $\psi$ and $\phi$ are varied in opposite senses is marked $C$. The latter was invariably the lowest energy route to rotation. The average values for barriers A, B and C are presented in Table 6. The data show that diphenylether and diphenylsulfide display very similar conformational energy surfaces and would therefore be expected to adopt similar conformations. Their type $C$ deformations vary very little in energy but the diphenylsulfide offers less resistance to deformations that increase the proximity of the two phenyl rings. The greater length of the $\mathrm{C}-\mathrm{S}$ bond compared with the $\mathrm{C}-\mathrm{O}$ bond leads to the phenyl rings being somewhat further
Table 6. Depths of potential wells from conformational grid searches of bisphenyl backbones

\begin{tabular}{|lccc|} 
& \multicolumn{3}{c|}{ Potential barrier to rotation $\left(\mathrm{kcal} \mathrm{mol}^{-1}\right)$} \\
\cline { 2 - 4 } Model compound & Type A & Type B & Type C \\
\hline Diphenyl ether & 20.59 & 6.07 & 2.73 \\
Diphenyl sulfide & 14.90 & 4.33 & 2.16 \\
\hline
\end{tabular}

apart in the diphenylsulfide, the reduced steric hindrance yielding a greater range of localized motions. The impact of this finding is shown in the greater resilience of the films in the $D$ series (comprising more thioether bridges).

The DSC rescan curves of the terpoly(methoxy-thiocyanuratecyanurate)s (Figs 4(b) and 5(b)) display some differences from 

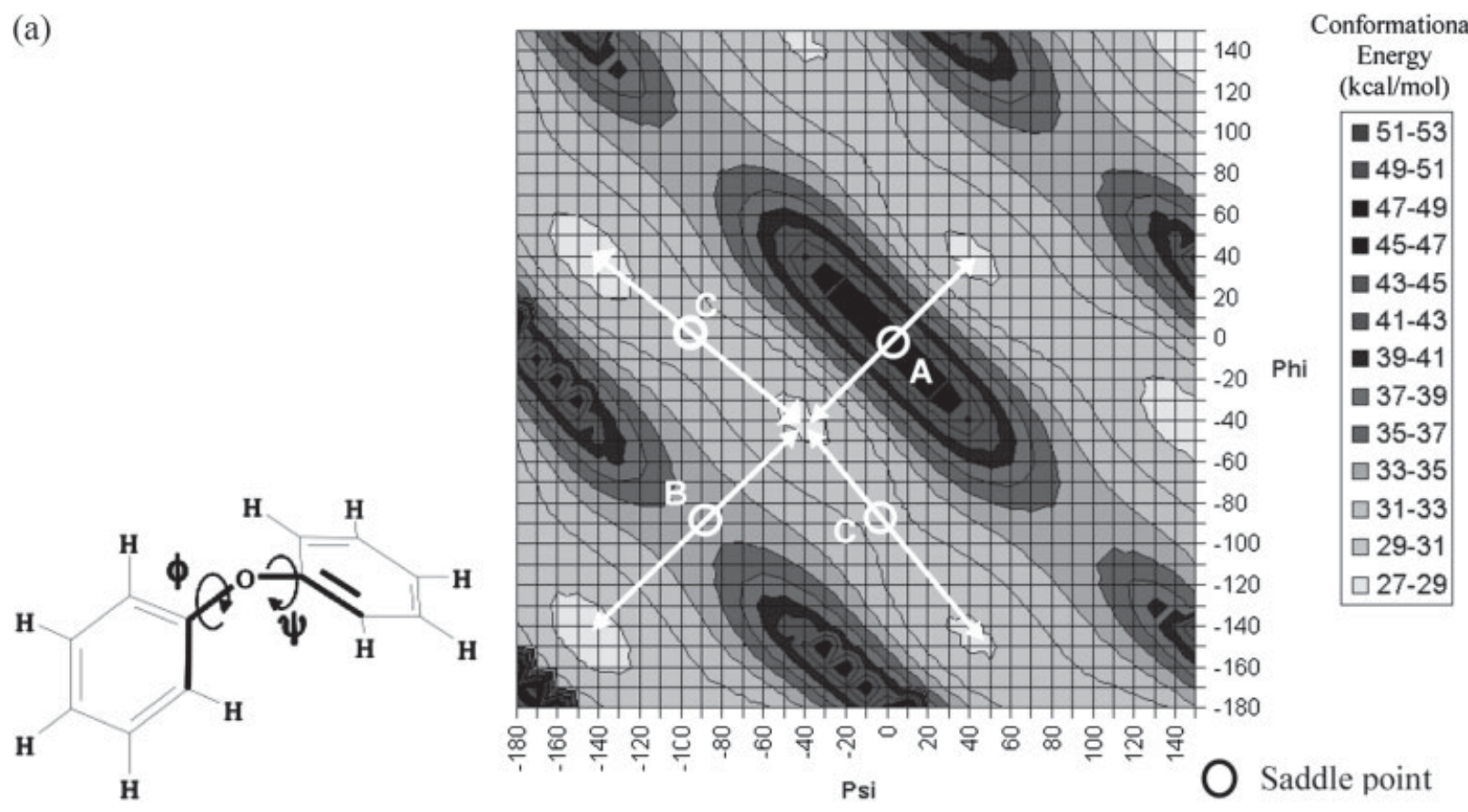

(b)

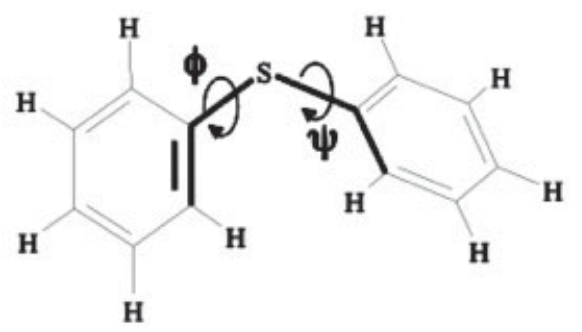

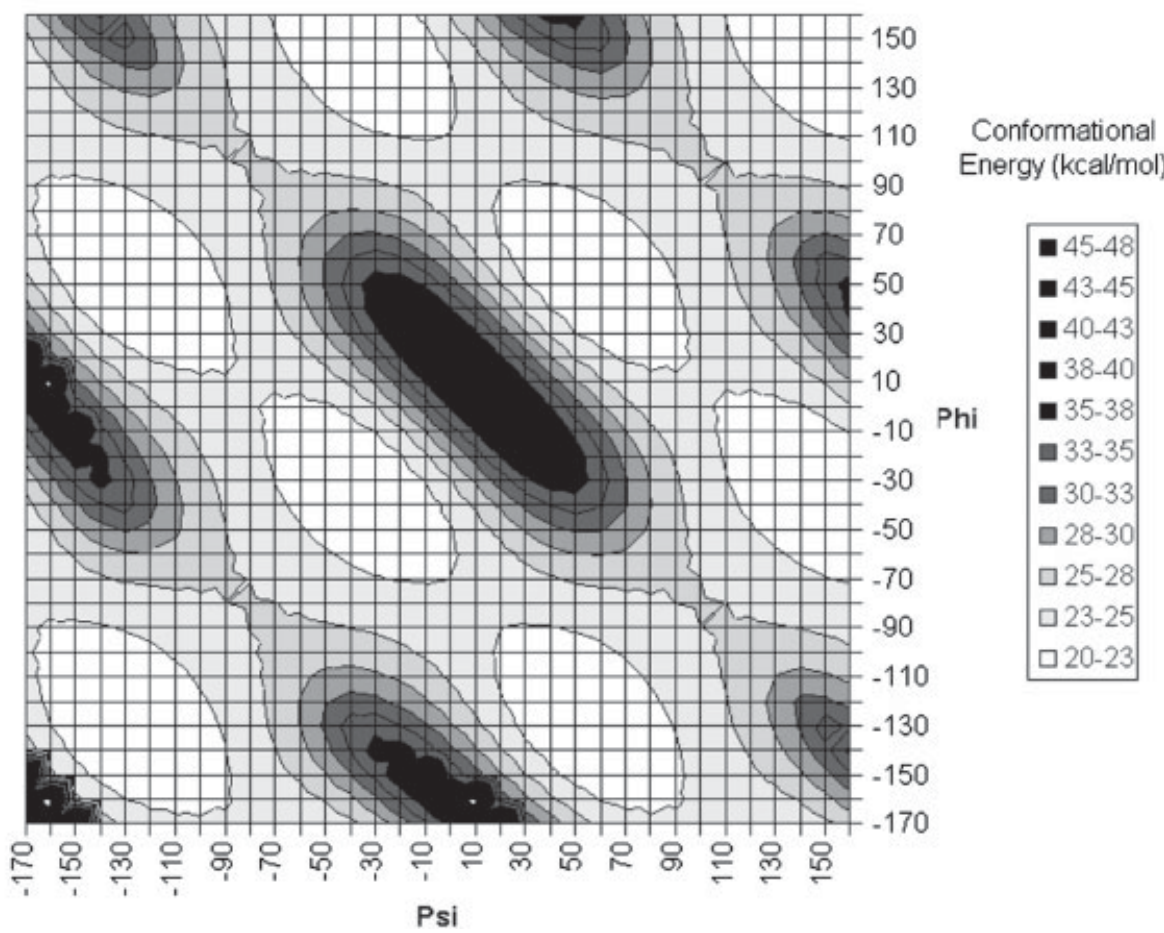

Figure 6. Conformational energy plots for (a) diphenylether and (b) diphenylsulfide (with backbone torsions of bisphenyl repeat units used for conformational grid searches shown). 


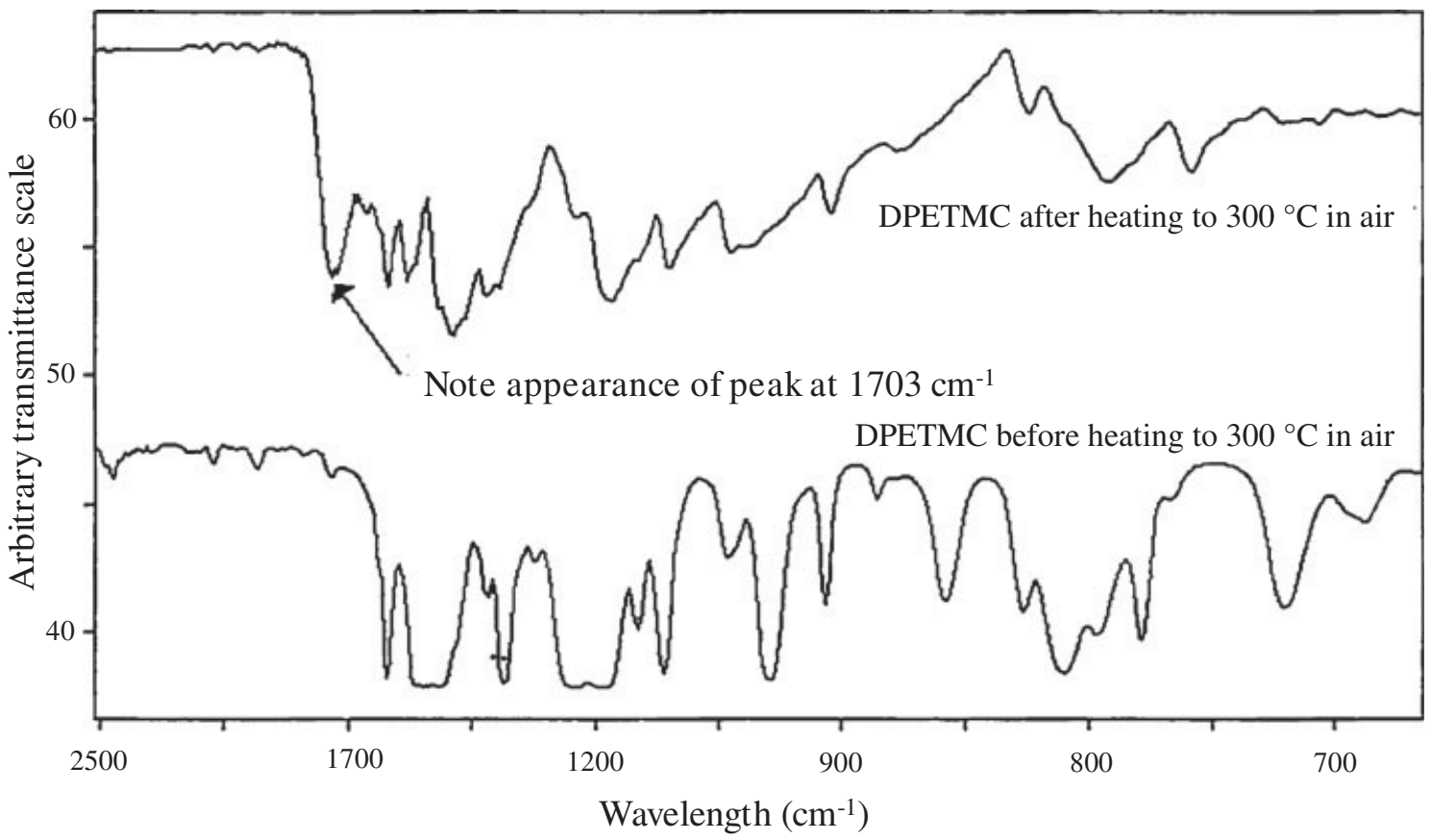

Figure 7. Comparison of DPETMC before and after heating to $300{ }^{\circ} \mathrm{C}$ in air at $10 \mathrm{~K} \mathrm{~min}^{-1}$.

previously reported homopolymers ${ }^{8}$ as the latter tend to exhibit single glass transitions of variable intensity between 190 and $220{ }^{\circ} \mathrm{C}$ while the transitions for the thiocyanurate polymers are found at lower temperatures $\left(144-175^{\circ} \mathrm{C}\right) .{ }^{4}$ This is consistent with the simulation data that suggest that the potential barriers to rotation for the aromatic sulfide linkages are somewhat lower $\left(14.90 \mathrm{kcal} \mathrm{mol}^{-1}\right)$ than the corresponding aromatic ether linkages (20.59 $\left.\mathrm{kcal} \mathrm{mol}^{-1}\right)$. Inspection of the CHN ratios (Table S2) for the heated sample (E1ANN) show that very little change in composition resulted. Elemental analysis, calculated for $\mathrm{C}_{32} \mathrm{H}_{22} \mathrm{~N}_{6} \mathrm{O}_{6} \mathrm{~S}_{2}$, gave $59.07 \%$ C, $3.41 \% \mathrm{H}, 12.92 \% \mathrm{~N}$; found $58.8 \% \mathrm{C}, 3.21 \% \mathrm{H}, 12.27 \% \mathrm{~N}$. Theoretical ratios were $\mathrm{C} / \mathrm{N} 4.57, \mathrm{C} / \mathrm{H}$ 17.33, N/H 3.79; found after heating, $\mathrm{C} / \mathrm{N} 4.79, \mathrm{C} / \mathrm{H} 18.32, \mathrm{~N} / \mathrm{H} 3.82$. This supports the hypothesis for isomerization above $200{ }^{\circ} \mathrm{C}$ which could not be accounted for by loss of solvent. Whilst no data are available for thiocyanurates, it has been known for many years that purely aliphatic cyanurates can be thermally unstable and isomerize readily to yield the corresponding isocyanurate. Trimethoxy-s-triazine isomerizes in the vapour phase when heated above $265^{\circ} \mathrm{C}$ with an enthalpy of $202.6 \mathrm{~kJ} \mathrm{~mol}^{-122}$ to give a reasonable estimate for the enthalpy of isomerization of a single methoxy-cyanurate unit; this figure was divided by three $\left(65.5 \mathrm{~kJ} \mathrm{~mol}^{-1}\right)$. The greatly reduced enthalpy observed in the DSC analysis of diphenoxymethoxy-s-triazine (13.6 $\mathrm{kJ} / \mathrm{mol}$ ) suggests that partial isomerization may be taking place. This is consistent with the findings of Tosato and Soccorsi who have shown, using NMR, that methyl transfer takes place between the methoxy oxygen and one of the two equivalent nitrogen atoms on the triazine ring at temperatures close to $200{ }^{\circ} \mathrm{C}$ in methoxy-cyanurates. ${ }^{29,30}$

In order to examine the proposed thermal isomerization, a sample of the DPEMTC was analysed using FTIR before and after heating to $300{ }^{\circ} \mathrm{C}$ under nitrogen at $10 \mathrm{~K} \mathrm{~min}^{-1}$. Examination of the spectra (Fig. 7) shows that a strong band becomes apparent at 1703 $\mathrm{cm}^{-1}$, which is consistent with the presence of a cyclic amide. ${ }^{31}$ Isomerization of the methoxy-triazine unit would introduce an exo-carbonyl group onto the ring and remove the triazine mode at $736 \mathrm{~cm}^{-1}$, which is indeed the case. Along with these data, a parallel TGA experiment was performed on DPEMTC. The TGA data show negligible weight loss upon heating to $300{ }^{\circ} \mathrm{C}$ and so it is reasonable to interpret these results as support for isomerization of some of the methoxy-triazine units taking place.

\section{CONCLUSIONS}

Aromatic bisthiophenols have been polymerized with dichlorotriazines to form high molecular weight materials in an analogous fashion to aromatic bisphenols. This work has shown that replacing a certain percentage of the thioether linkages in the copoly(methoxy-thiocyanurate)s with ether linkages increases the flexibility of the resulting polymers and decreases their tendency to precipitate from solution. Increasing the sulfur content of the polymers appears to reduce their solubility in non-chlorinated solvents considerably and seems to afford lower solvent retention when the polymers are cast from solutions in dichloromethane. Comparing the qualitative resilience of samples E2 and E4 (which are of equivalent molecular weight) demonstrates clearly that increasing the percentage of thioether linkages in the backbone of the polymers increases their brittleness quite considerably. The almost statistical co-reaction of the thiophenol and phenol moieties in the polymerization mixture with MDCT has been shown by NMR to produce three different methoxy-triazine units.

\section{ACKNOWLEDGEMENT}

We thank the Ministry of Defence (formerly DRA, Malvern) for providing sponsorship in the form of a studentship (DAT).

\section{SUPPORTING INFORMATION}

Supporting information may be found in the online version of this article. 


\section{REFERENCES}

1 Picklesmeyer LG and Saunders TF, J Polym Sci Polym Chem 3: 2679 (1965).

2 Audebert R and Néel J, Comptes Rendus Acad Sci Paris T258: 4749 (1964).

3 Nakamura Y, Mori K, Tamura K and Saito Y, J Polym Sci Polym Chem 7 : 3089 (1969).

4 Hamerton I, Howlin BJ and Tilbrook DA, (2013) submitted.

5 Barron PF, Hill DJT, O'Donnel JH and O'Sullivan PW, Macromolecules 17: 1967 (1994).

6 Shimadzu Corporation, DSC-50 Service Manual. Tokyo, Japan (1993).

7 Fletcher R and Reeves CM, J Comput 7: 149 (1964).

8 Casewit CJ, Colwell KS and Rappé AK, Am Chem Soc 114: 10035 (1992).

9 Casewit CJ, Colwell KS and Rappé AK, J Am Chem Soc 114: 10046 (1992).

10 Stewart JP, J Comput-Aided Mol Des 4: 1 (1990).

11 Shah PP, J Macromol Sci Chem Ed 84: 715 (1984).

12 Braun D and Ziser T, Angew Makromol Chem 219: 27 (1994).

13 Hamerton I, Howlin BJ and Tilbrook DA, React Func Polym $\mathbf{7 3}$ 1046-1057 (2013).

14 Padgett WM and Hamner WF, J Am Chem Soc 80: 803 (1958).

15 Vargani V, Kansard SS and Patel NK, J Macromol Sci A28: 193 (1991).

16 Kalola SH and Parsania PH, J Polym Mater 11: 101 (1994).

17 Kamani MM and Parsania PH, J Polym Mater 12: 49 (1995).
18 Fang T, Macromolecules 24: 444 (1991).

19 Fyfe CA, Niu J, Rettig SJ and Burlinson NE, Macromolecules 25: 6289 (1992).

20 Cowie JMG, Polymers: Chemistry and Physics of Modern Materials. WileyScience, New York (1991).

21 Braun D, Most D and Ziser T, Angew Makromol Chem 221: 187 (1994).

22 Ramirez ML, Walters R, Lyon RE and Savitski EP, Polym Deg Stab 78: 73-82 (2002).

23 Hamerton I, in Chemistry and Technology of Cyanate Ester Resins, ed. by Hamerton I. Blackie Academic and Professional, Glasgow, pp. 202-205 (1994).

24 Japanese Standard JIS K 7122, Thermal Analysis of Polymeric Materials. Shimadzu Corporation, Tokyo, Japan (1992).

25 Parsania PH, Shah PP, Patel KC and Patel RD, Angew Makromol Chem 138: 139 (1984).

26 Parsania PH, Patel KC and Patel RD, J Polym Sci Polym Phys 23: 199 (1984).

27 Kalola SH, Gelam PH and Parsania PH, J Polym Mater 11: 57 (1994).

28 Sun T, Pereriera J and Porter RS, J Polym Sci Polym Phys 22: 1163 (1984).

29 Tosato ML and Soccorsi L, J Chem Soc Perkin II 1321 (1982).

30 Tosato ML and Soccorsi L, J Chem Soc Perkin II 1593 (1984).

31 Silverstein RM and Webster FX, Spectrometric Identification of Organic Compounds, 6th edn. Wiley, New York, pp. 101-102 (1998). 